\title{
Parâmetros metabólicos de pacus alimentados com diferentes fontes de óleo
}

\author{
Paula Adriane Perez Ribeiro ${ }^{(1)}$, Leandro Santos Costa ${ }^{(2)}$, Raquel Tatiane Pereira(2), \\ Luis Davis Solis Murgas ${ }^{(2)}$ e Priscila Vieira e Rosa ${ }^{(2)}$
}

\begin{abstract}
(1)Universidade Federal de Minas Gerais, Escola de Veterinária, Departamento de Zootecnia, Laboratório de Aquacultura, Avenida Antônio Carlos, o 6.627, CEP 31270-901 Belo Horizonte, MG. E-mail: paulaperezribeiro@hotmail.com (2)Universidade Federal de Lavras, Departamento de Zootecnia, Campus Universitário, Caixa Postal 3.037, CEP 37200-000 Lavras, MG. E-mail: leandrocapitoliomg@yahoo.com.br, geninhaufla@hotmail.com, Ismurgas@ufla.br, priscila@dzo.ufla.br
\end{abstract}

Resumo - O objetivo deste trabalho foi avaliar parâmetros metabólicos de pacus (Piaractus mesopotamicus) alimentados com dietas com diferentes óleos. O experimento foi conduzido em laboratório, em maio de 2009, durante 28 dias. Foram utilizados 64 pacus com peso inicial de $61 \mathrm{~g}$, mantidos em tanques de $250 \mathrm{~L}$. Os tratamentos foram: dieta controle mais óleo de oliva; dieta controle mais óleo de milho; dieta controle mais óleo de peixe; e dieta controle mais óleo de milho e de peixe. Utilizou-se o delineamento inteiramente casualizado, com quatro repetições, em arranjo fatorial 4x4 (quatro dietas e quatro tempos de coleta: 7, 14, 21 e 28 dias). Foram avaliados: níveis sanguíneos de colesterol e lipoproteínas, composição química muscular, e atividade de glicose-6-fosfato desidrogenase (G6PD) e enzima málica (EM). Os dados foram submetidos à análise de variância, à comparação das médias pelo teste de Tukey, e à análise de regressão. Não houve diferença nos teores musculares de umidade e cinzas, mas foram observadas alterações na deposição lipídica e proteica, conforme os tempos de coleta, em todos os tratamentos. As dietas interferiram nos parâmetros sanguíneos avaliados. A atividade de G6PD é superior à da EM, sendo maior nos animais alimentados com óleo de oliva e milho, o que sugere maior deposição lipídica muscular nestes peixes. Portanto, o metabolismo lipídico do pacu é influenciado pela composição do lipídio da dieta.

Termos para indexação: Piaractus mesopotamicus, ácido graxo, enzimas, nutrição, peixe.

\section{Metabolic parameters of pacu fed different oil sources}

\begin{abstract}
The objective of this work was to evaluate the metabolic parameters of pacu (Piaractus mesopotamicus) fed diets with different oils. The experiment was conducted in the laboratory, on May 2009, during 28 days. Sixty four fish with initial weight of $61 \mathrm{~g}$, kept in $250 \mathrm{~L}$ tanks, were used. The treatments were: control diet plus olive oil; control diet plus corn oil; control diet plus fish oil; and control diet plus corn oil and fish oil. A completely randomized design was used, with four replicates and a $4 \times 4$ factorial arrangement (four diets and four sampling times: 7, 14, 21, and 28 days). The following were evaluated: cholesterol and lipoprotein blood levels, muscle chemical composition, and activity of glucose-6-phosphate dehydrogenase (G6PD) and malic enzyme (ME). The data were subjected to analysis of variance, comparisons of means using the Tukey test, and to regression analysis. There were no differences in muscle levels of moisture or ash, but changes were observed in lipid and protein deposition, depending on collection time, for all treatments. The diets interfered in the evaluated blood parameters. G6PD activity is higher than that of ME, being higher in animals fed with olive and corn oil, suggesting more lipid deposition in the muscles of these fish. Therefore, the lipid metabolism of pacu is influenced by the lipid composition of the diet.
\end{abstract}

Index terms: Piaractus mesopotamicus, fatty acid, enzymes, nutrition, fish.

\section{Introdução}

A relação entre os lipídios da dieta, bem como o desenvolvimento de doenças crônico-degenerativas, tem sido de interesse nas áreas de nutrição animal e humana. Problemas cardiovasculares decorrentes da aterosclerose estão diretamente relacionados ao elevado consumo de lipídios, sobretudo na forma de colesterol, gorduras saturadas e óleos transinsaturados, comumente presentes em alimentos de origem animal. No entanto, algumas classes de lipídios, como os ácidos graxos poli-insaturados, trazem benefícios maiores à saúde.

Entre as fontes de ácidos graxos mais comumente utilizadas na alimentação animal, destacam-se alguns óleos vegetais e animais. Óleos, como os de soja e linhaça, apresentam altos teores de ácido a-linolênico, precursor 
do ácido eicosapentaenoico (EPA) e do docosahexaenoico (DHA). Estes últimos são superiores aos óleos de milho e girassol (Pereira et al., 2003). O óleo de peixe, comumente obtido de espécies marinhas, é rico em EPA e DHA, porém, é de alto custo para a indústria de rações. Encontrar alternativas para substituí-lo, parcial ou totalmente, nas rações para peixes, sem prejudicar o metabolismo dos animais, representaria um benefício ao mercado.

As principais rotas lipogênicas apresentam grande variação entre as espécies, tanto na sua disposição tecidual, quanto nos substratos para a síntese lipídica. Em peixes, estas vias metabólicas são, geralmente, comparáveis às da maioria dos mamíferos. Assim, os ácidos graxos oriundos da quebra dos lipídios da dieta podem ser incorporados aos fosfolipídios, armazenados como lipídios de reserva ou oxidados para fornecer energia (Menoyo et al., 2003).

A taxa lipogênica em espécies de água doce é fortemente regulada por fatores nutricionais. Sabe-se, por exemplo, que os lipídios da dieta podem suprimir a lipogênese (Tocher, 2003). Estudos com "turbot" [Psetta máxima (Linnaeus, 1758)] mostram que a atividade de enzimas hepáticas que participam dos processos de lipogênese como a glicose-6-fosfato desidrogenase, a enzima málica e a acetil-CoA carboxilase - responde às variações na quantidade e na qualidade dos lipídios da dieta (Regost et al., 2001).

As diferentes fontes lipídicas influenciam os processos lipogênicos no organismo; entretanto, o grau desta influência depende da espécie em questão. Pesquisas realizadas com carpa comum evidenciam que dietas com ácidos graxos poli-insaturados ômega- 3 reduzem a lipogênese no hepatopâncreas desses peixes. Dietas com altos teores de lipídios também são responsáveis pela redução da atividade específica e da eficiência catalítica da glicose-6-fosfato desidrogenase em peixes, além de causarem alterações nos teores de colesterol circulante e de lipoproteínas plasmáticas (Sánchez-Muros et al., 1996; Richard et al., 2006a).

O pacu [Piaractus mesopotamicus (Holmberg, 1887)] é uma das espécies nativas de interesse comercial no Brasil. Contudo, a tendência para depositar gordura corporal, principalmente na cavidade abdominal, é recorrente, o que altera a palatabilidade da carne e reduz seu valor de mercado. Assim, o conhecimento do metabolismo lipídico desta espécie é ferramenta indispensável para a elaboração de dietas equilibradas, que proporcionem bom desempenho e qualidade de carne satisfatória.
O objetivo deste trabalho foi avaliar parâmetros metabólicos de pacus alimentados com dietas com diferentes óleos.

\section{Material e Métodos}

O experimento foi conduzido no Laboratório de Nutrição de Peixes da Universidade Federal de Lavras, MG, em maio de 2009, o que totalizou 28 dias. Foram utilizados 64 juvenis de pacu, com peso médio inicial de $61 \pm 6 \mathrm{~g}$, alojados em oito caixas de metabolismo, com capacidade para $250 \mathrm{~L}$. Utilizou-se o delineamento experimental inteiramente casualizado, com quatro repetições e tratamentos dispostos em arranjo fatorial $4 \mathrm{x} 4$. Os tratamentos consistiram de quatro dietas (dieta controle mais óleo de oliva, dieta controle mais óleo de milho, dieta controle mais óleo de peixe, e dieta controle mais óleo de milho e óleo de peixe) e quatro tempos de coleta $(7,14$, 21 e 28 dias). A composição das dietas experimentais e o perfil de ácidos graxos estão descritos nas Tabelas 1 e 2, respectivamente.

O consumo médio diário de ração foi de $5 \%$ do peso vivo. A ração foi fornecida duas vezes ao dia (às $8 \mathrm{~h}$ e

Tabela 1. Composição das rações experimentais formuladas para pacu.

\begin{tabular}{|c|c|c|c|c|}
\hline \multirow{2}{*}{$\begin{array}{l}\text { Ingrediente } \\
(\%)\end{array}$} & \multicolumn{4}{|c|}{ Tratamentos (dietas) } \\
\hline & $\begin{array}{l}\text { Óleo de } \\
\text { oliva }\end{array}$ & $\begin{array}{l}\text { Óleo de } \\
\text { milho }\end{array}$ & $\begin{array}{l}\text { Óleo de } \\
\text { peixe }\end{array}$ & $\begin{array}{l}\text { Óleo de milho } \\
\text { e peixe }{ }^{(1)}\end{array}$ \\
\hline Proteína isolada de soja & 26,65 & 26,65 & 26,65 & 26,65 \\
\hline Gelatina & 13,33 & 13,33 & 13,33 & 13,33 \\
\hline Amido de milho & 48,00 & 48,00 & 48,00 & 48,00 \\
\hline Celulose & 6,00 & 6,00 & 6,00 & 6,00 \\
\hline Óleo de oliva & 4,00 & - & - & - \\
\hline Óleo de milho & - & 4,00 & - & - \\
\hline Óleo de peixe & - & - & 4,00 & - \\
\hline Óleo de milho e peixe ${ }^{(1)}$ & - & - & - & 4,00 \\
\hline Fosfato bicálcico & 1,50 & 1,50 & 1,50 & 1,50 \\
\hline Suplemento vitamínico ${ }^{(2)}$ & 0,33 & 0,33 & 0,33 & 0,33 \\
\hline Suplemento mineral $^{(3)}$ & 0,17 & 0,17 & 0,17 & 0,17 \\
\hline Antioxidante & 0,02 & 0,02 & 0,02 & 0,02 \\
\hline Proteína bruta (\%) & 33,92 & 33,97 & 34,03 & 33,89 \\
\hline Energia bruta $\left(\mathrm{kcal} \mathrm{kg}^{-1}\right)$ & $4.012,35$ & $4.028,40$ & $3.997,88$ & $4.073,25$ \\
\hline Extrato etéreo (\%) & 10,80 & 10,63 & 10,98 & 10,94 \\
\hline Cálcio (\%) & 0,42 & 0,40 & 0,42 & 0,40 \\
\hline Fósforo (\%) & 0,43 & 0,41 & 0,44 & 0,41 \\
\hline \multicolumn{5}{|c|}{$\begin{array}{l}\text { (1) } 50 \% \text { de óleo de milho mais } 50 \% \text { de óleo de peixe. }{ }^{(2)} \text { Composição do } \\
\text { suplemento vitamínico (quantidade por quilograma de premix): vitamina } \\
\text { A, } 1.500 \mathrm{UI} \text {; vitamina B1, } 20 \mathrm{mg} \text {; vitamina B2, } 15 \mathrm{mg} \text {; vitamina B3, } 1.000 \\
\text { UI; vitamina B12, } 10 \mu c g \text {; vitamina } \mathrm{E}, 25 \mathrm{mg} \text {; vitamina PP, } 120 \mathrm{mg} \text {; colina, } \\
2.000 \mathrm{mg} \text {; pantotenato de cálcio, } 80 \mathrm{mg} \text {; ácido fólico, } 2 \mathrm{mg} \text {; butil hidroxito- } \\
\text { lueno, } 170 \mathrm{mg} \text {. }{ }^{(3)} \text { Composição do suplemento mineral (quantidade por qui- } \\
\text { lograma de premix): manganês, } 80 \mathrm{mg} \text {; ferro, } 24 \mathrm{mg} \text {; zinco, } 50 \mathrm{mg} \text {; cobre, } \\
8 \mathrm{mg} \text {; iodo, } 3 \mathrm{mg} \text {; selênio, } 0,10 \mathrm{mg} \text {. }\end{array}$} \\
\hline
\end{tabular}

Pesq. agropec. bras., Brasília, v.48, n.8, p.1035-1042, ago. 2013 DOI: 10.1590/S0100-204X2013000800032 
às $16 \mathrm{~h}$ ). No momento do fornecimento da ração, foram monitorados os parâmetros limnológicos nas caixas de metabolismo. A temperatura da água e o teor de oxigênio foram mensurados por oxímetro digital YSI 55, (YSI Incorporated, Yellow Springs, OH, EUA), e o pH, com auxílio de kit comercial Labcon Test, (Alcon Ltda., Camboriú, SC). A retirada dos restos de ração e das excretas das caixas foi feita por sifonagem diária.

Em cada tempo de coleta, quatro animais de cada tratamento foram mantidos em jejum por 24 horas, anestesiados com benzocaína (50 $\mathrm{mg} \mathrm{L}^{-1}$ ), para coleta de sangue por punção cardíaca. As amostras foram centrifugadas (3.000 rpm, $10 \mathrm{~min}$ ) para separação do plasma. As análises de colesterol total, lipoproteína de alta densidade (HDL), lipoproteína de baixa densidade (LDL) e lipoproteína de densidade muito baixa (VLDL) foram realizadas por método enzimático-fotométrico, com uso de kits comerciais (Gold Analisa Diagnóstica Ltda., Belo Horizonte, MG).

Ao final das coletas de sangue, os animais foram abatidos, eviscerados - com separação do fígado, para

Tabela 2. Perfil de ácidos graxos das dietas experimentais formuladas para pacu.

\begin{tabular}{|c|c|c|c|c|}
\hline \multirow{2}{*}{$\begin{array}{l}\text { Ácido graxo } \\
(\%)\end{array}$} & \multicolumn{4}{|c|}{ Tratamentos (dietas) } \\
\hline & $\begin{array}{l}\text { Óleo de } \\
\text { oliva }\end{array}$ & $\begin{array}{l}\text { Óleo de } \\
\text { milho }\end{array}$ & $\begin{array}{l}\text { Óleo de } \\
\text { peixe }\end{array}$ & $\begin{array}{c}\text { Óleo de milho } \\
\text { e peixe }^{(1)}\end{array}$ \\
\hline C 14:0 & 2,05 & 2,01 & 5,30 & 1,86 \\
\hline C $14: 1 \mathrm{n}-5$ & 0,10 & 0,07 & 0,09 & 0,11 \\
\hline C 16:0 & 17,90 & 20,28 & 19,35 & 15,48 \\
\hline C $16: 1 \mathrm{n}-7$ & 4,68 & 3,86 & 0,00 & 0,04 \\
\hline C 17:0 & 0,32 & 0,21 & 0,22 & 0,17 \\
\hline C $17: 1 \mathrm{n}-7$ & 0,06 & 0,10 & 0,88 & 0,13 \\
\hline C 18:0 & 30,98 & 15,56 & 18,13 & 20,97 \\
\hline C $18: 1 \mathrm{n}-9$ & 17,99 & 7,79 & 5,42 & 10,68 \\
\hline C $18: 2 n-6$ & 11,82 & 22,73 & 10,07 & 38,38 \\
\hline C $18: 3 n-3$ & 0,70 & 0,45 & 3,31 & 6,03 \\
\hline C 20:0 & 0,00 & 0,00 & 0,00 & 0,54 \\
\hline C 20:1 n-9 & 1,25 & 1,41 & 2,82 & 0,44 \\
\hline C 20:2n-6 & 1,23 & 1,28 & 0,72 & 0,21 \\
\hline C $20: 3 n-6$ & 1,32 & 1,47 & 0,28 & 0,10 \\
\hline C 20:4 n-6 & 5,14 & 5,74 & 0,76 & 0,27 \\
\hline C $20: 5 n-3$ & 1,39 & 1,87 & 6,69 & 0,27 \\
\hline C 22:6 n-3 & 1,22 & 1,17 & 9,81 & 0,17 \\
\hline$n-3$ & 3,31 & 3,49 & 19,81 & 6,47 \\
\hline$n-6$ & 19,51 & 31,22 & 11,83 & 38,96 \\
\hline$n-9$ & 19,24 & 9,20 & 8,24 & 11,12 \\
\hline Saturados & 51,25 & 38,06 & 43,00 & 39,02 \\
\hline Monoinsaturados & 24,08 & 13,23 & 9,21 & 11,40 \\
\hline Poli-insaturados & 22,82 & 34,71 & 31,64 & 45,43 \\
\hline$n-3 / n-6$ & 0,17 & 0,11 & 1,67 & 0,17 \\
\hline
\end{tabular}

(1) $50 \%$ de óleo de milho mais $50 \%$ de óleo de peixe. posterior análise - e filetados. As amostras de tecido muscular foram analisadas para determinação dos teores de umidade, proteína, cinzas e extrato etéreo, segundo Horwitz (2005). As amostras de fígado foram submetidas ao processo de obtenção de extratos celulares, conforme metodologia adaptada por Ribeiro et al. (2008). Os extratos de células hepáticas foram homogeneizados em tampão HEPES-KOH $25 \mathrm{mmol} \mathrm{L}^{-1}$ (Sigma-Aldrich Brasil, Ltda., São Paulo, SP) de pH 7,2 e centrifugadas $\left(10.000 \mathrm{rpm}, 4^{\circ} \mathrm{C}\right.$, $30 \mathrm{~min}$ ) para análise das atividades de glicose-6-fosfato desidrogenase (G6PD, E.C.1.1.1.49), de acordo com Graeve (1994), e de enzima málica (EM, E.C.1.1.1.40), segundo Spina Junior et al. (1970). A cinética enzimática foi monitorada por espectrofotometria ultravioleta, com equipamento SpectroUV, acoplado ao programa UVWin v.5.0.1. O conteúdo de proteína solúvel total do fígado foi determinado pelo método de Bradford (1976), tendo-se utilizado albumina sérica bovina como padrão.

As análises estatísticas foram realizadas com auxílio do programa SAEG (2007), e as médias dos tratamentos foram comparadas pelo teste de Tukey, a 5\% de probabilidade. Os tempos de coleta foram submetidos à análise de regressão.

\section{Resultados e Discussão}

Os parâmetros limnológicos mantiveram-se dentro das faixas normais para pacu. Os valores médios de $\mathrm{pH}$, oxigênio dissolvido e temperatura foram: $6,8 \pm 0,1$, $4,95 \pm 0,71 \mathrm{mg} \mathrm{L}^{-1}$ e $24,1 \pm 1,2^{\circ} \mathrm{C}$, respectivamente. $\mathrm{O}$ peso médio final dos peixes foi de $85 \pm 5,89 \pm 9,85 \pm 8$ e $77 \pm 8 \mathrm{~g}$, para os animais que receberam dieta com óleo de oliva, óleo de milho, óleo de peixe e óleo de milho mais óleo de peixe, respectivamente.

Os tratamentos aplicados não interferiram significativamente nos teores de umidade e cinzas do músculo dos animais. Porém, houve efeito significativo dos tratamentos sobre a percentagem de lipídios e de proteína. Também houve interação significativa entre as dietas e os tempos de coleta estudados, para proteína e extrato etéreo (Tabela 3 ).

Os animais alimentados com dietas isoproteicas, isoenergéticas e sem variações nos teores lipídicos totais normalmente não mostram diferenças na composição química (Menoyo et al., 2003). No entanto, observaram-se alterações significativas nos teores de extrato etéreo e de proteína. Os animais alimentados com dietas com óleo de oliva, óleo de milho e uma mistura de óleo de milho e óleo de peixe tiveram maior deposição lipídica muscular, aos 
21 e 28 dias, em comparação aos animais que receberam óleo de peixe puro. Este fato pode estar associado à maior atividade de enzimas lipogênicas, favorecida pela composição em ácidos graxos dos lipídios das dietas, situação esta que proporciona um processo lipogênico mais acentuado. Isso está de acordo com o observado por Ribeiro et al. (2008), ao estudar o metabolismo lipídico da tilápia nilótica alimentada com dietas semelhantes. Apesar das variações verificadas para estes parâmetros, as médias encontradas se aproximam das relatadas por Furuya et al. (2000), Luzia et al. (2003) e Aiura \& Carvalho (2007), ao se desconsiderar as diferenças atribuídas às condições em que as pesquisas foram realizadas.

Ostratamentosaplicadosinterferiram significativamente nos parâmetros sanguíneos avaliados, e influenciaram os teores de colesterol total e das lipoproteínas plasmáticas HDL e VLDL dos peixes. Não houve influência dos tratamentos nos teores de LDL. Entretanto, observou-se interação significativa entre as dietas e os tempos de coleta nos teores de colesterol, HDL e VLDL (Tabela 4).

Nos peixes alimentados com dietas com óleo de peixe, as concentrações de colesterol total foram mais elevadas que nos animais que receberam as demais dietas. Isso, possivelmente, também é reflexo do colesterol presente na dieta, uma vez que esta foi elaborada com óleo de origem animal. Richard et al. (2006b?) obtiveram resultados semelhantes ao avaliar os mesmos parâmetros no metabolismo do seabass [Dicentrarchus labrax (Linnaeus, 1758)].

O transporte de ácidos graxos e outros componentes lipídicos para tecidos periféricos é mediado por lipoproteínas. Desse modo, a composição e a quantidade de ácidos graxos ingeridos na dieta influenciam os teores de lipoproteínas circulantes, bem como sua composição (Torstensen et al., 2001, 2004; Jordal et al., 2007). Os níveis de HDL foram mais elevados nos animais alimentados com dieta à base de óleo de peixe, quando comparado aos animais que receberam os demais tratamentos. Este aumento se deve à composição desta dieta, rica em EPA e DHA. Além disso, a HDL é a classe de lipoproteínas predominante em peixes teleósteos, principalmente em espécies onívoras de água doce (Ferreira et al., 2011).

Apesar de Gilman et al. (2003) relatarem que óleos vegetais, como os de oliva e canola, podem reduzir os níveis de LDL circulantes, por determinarem diminuição na absorção intestinal do colesterol, no presente trabalho, não foi observado efeito sobre os teores desta lipoproteína.

Verificou-se que dietas contendo óleo de milho puro, quando fornecidas aos peixes por período superior a

Tabela 3. Valores médios (\%) de umidade, proteína, extrato etéreo e cinzas, na matéria seca, do músculo dos pacus, de acordo com a dieta fornecida e o tempo de coleta $^{(1)}$.

\begin{tabular}{|c|c|c|c|c|}
\hline \multirow[t]{2}{*}{ Dieta } & \multicolumn{4}{|c|}{ Tempo de coleta (dias) } \\
\hline & 7 & 14 & 21 & 28 \\
\hline & \multicolumn{4}{|c|}{ Umidade } \\
\hline Óleo de oliva & $75,91 \pm 6,12$ & $79,84 \pm 0,90$ & $77,43 \pm 1,39$ & $79,03 \pm 0,43$ \\
\hline Óleo de milho & $79,60 \pm 0,83$ & $79,67 \pm 0,70$ & $78,79 \pm 0,95$ & $79,73 \pm 0,44$ \\
\hline Óleo de peixe & $79,16 \pm 0,42$ & $78,52 \pm 1,00$ & $78,50 \pm 0,98$ & $79,45 \pm 0,73$ \\
\hline \multirow[t]{2}{*}{ Óleo de milho (50\%) mais óleo de peixe $(50 \%)$} & $80,84 \pm 0,63$ & $79,93 \pm 0,42$ & $79,18 \pm 1,01$ & $79,42 \pm 1,01$ \\
\hline & \multicolumn{4}{|c|}{ Proteína } \\
\hline Óleo de oliva & $43,98 \pm 2,84 \mathrm{aC}$ & $42,17 \pm 0,49 \mathrm{aC}$ & $54,93 \pm 2,15 \mathrm{aB}$ & $60,35 \pm 1,19 \mathrm{aA}$ \\
\hline Óleo de milho & $38,46 \pm 2,39 \mathrm{aB}$ & $36,81 \pm 1,59 \mathrm{aB}$ & $49,10 \pm 1,14 \mathrm{aA}$ & $52,09 \pm 2,59 \mathrm{aA}$ \\
\hline Óleo de peixe & $46,14 \pm 3,38 \mathrm{aD}$ & $53,53 \pm 2,58 \mathrm{aC}$ & $58,88 \pm 1,35 \mathrm{aB}$ & $65,46 \pm 1,02 \mathrm{aA}$ \\
\hline \multirow[t]{2}{*}{ Óleo de milho (50\%) mais óleo de peixe $(50 \%)$} & $36,67 \pm 1,86 \mathrm{aD}$ & $45,35 \pm 2,95 \mathrm{aC}$ & $55,28 \pm 2,59 \mathrm{aB}$ & $61,77 \pm 2,50 \mathrm{aA}$ \\
\hline & \multicolumn{4}{|c|}{ Extrato etéreo } \\
\hline Óleo de oliva & $15,23 \pm 0,23 \mathrm{aA}$ & $15,31 \pm 0,43 \mathrm{aB}$ & $15,40 \pm 0,26 \mathrm{aB}$ & $16,75 \pm 0,15 \mathrm{aB}$ \\
\hline Óleo de milho & $16,32 \pm 0,25 \mathrm{aB}$ & $16,80 \pm 0,38 \mathrm{aAB}$ & $17,16 \pm 0,09 \mathrm{aA}$ & $16,92 \pm 0,31 \mathrm{aAB}$ \\
\hline Óleo de peixe & $14,47 \pm 0,17 \mathrm{aA}$ & $13,87 \pm 0,15 \mathrm{aA}$ & $11,61 \pm 0,66 \mathrm{bB}$ & $10,38 \pm 0,35 b \mathrm{~b}$ \\
\hline \multirow[t]{2}{*}{ Óleo de milho $(50 \%)$ mais óleo de peixe $(50 \%)$} & $16,72 \pm 0,31 \mathrm{aA}$ & $15,91 \pm 0,29 \mathrm{aB}$ & $15,16 \pm 0,63 \mathrm{aB}$ & $15,20 \pm 0,56 \mathrm{aB}$ \\
\hline & \multicolumn{4}{|c|}{ Cinzas } \\
\hline Óleo de oliva & $5,33 \pm 1,19$ & $6,32 \pm 0,38$ & $5,16 \pm 0,41$ & $5,11 \pm 0,15$ \\
\hline Óleo de milho & $5,70 \pm 0,16$ & $5,16 \pm 0,16$ & $4,83 \pm 0,16$ & $5,51 \pm 0,17$ \\
\hline Óleo de peixe & $6,07 \pm 0,05$ & $5,11 \pm 0,23$ & $4,68 \pm 0,28$ & $5,52 \pm 0,24$ \\
\hline Óleo de milho $(50 \%)$ mais óleo de peixe $(50 \%)$ & $5,38 \pm 0,37$ & $5,75 \pm 0,03$ & $5,63 \pm 0,31$ & $5,22 \pm 0,22$ \\
\hline
\end{tabular}

${ }^{(1)}$ Médias seguidas de letras iguais, maiúsculas nas linhas e minúsculas nas colunas, não diferem, entre si, pelo teste de Tukey, a 5\% de probabilidade. 
sete dias, resultaram em maiores teores de VLDL, em comparação aos demais tratamentos, o que reflete um possível efeito hipercolesterolêmico. Contudo, a mistura com óleo de peixe (50\% óleo de milho e $50 \%$ óleo de peixe) reduz significativamente este efeito e promove resultados semelhantes aos obtidos em animais alimentados com dietas contendo exclusivamente óleo de peixe. Richard et al. (2006b), ao avaliar o efeito colesterolêmico da substituição de óleo de peixe por fontes vegetais em rações para Dicentrarchus labrax, também constataram a interferência do perfil de ácidos graxos dos óleos utilizados em dietas animais sobre lipoproteínas de baixa densidade.

As dietas fornecidas aos pacus interferiram significativamente na atividade das enzimas málica e G6PD. O tempo de coleta das amostras foi significativo apenas para a enzima málica, uma vez que houve redução na sua atividade, de acordo com o aumento no tempo de coleta (Tabela 5 e Figura 1).

Tabela 4. Valores médios de colesterol, lipoproteína de alta densidade (HDL), lipoproteína de baixa densidade (LDL), lipoproteína de densidade muito baixa (VLDL) e triglicerídeos $\left(\mathrm{mg} \mathrm{mL}^{-1}\right)$ em pacus, de acordo com a dieta fornecida e o tempo de coleta $^{(1)}$.

\begin{tabular}{|c|c|c|c|c|}
\hline \multirow[t]{2}{*}{ Dieta } & \multicolumn{4}{|c|}{ Tempo de coleta (dias) } \\
\hline & 7 & 14 & 21 & 28 \\
\hline & \multicolumn{4}{|c|}{ Colesterol sérico } \\
\hline Óleo de oliva & $90,79 \pm 5,34 \mathrm{cB}$ & $91,54 \pm 1,63 \mathrm{cB}$ & $97,13 \pm 1,62 \mathrm{cA}$ & $100,60 \pm 1,09 \mathrm{cA}$ \\
\hline Óleo de milho & $101,51 \pm 1,54 \mathrm{bD}$ & $111,03 \pm 4,06 \mathrm{bC}$ & $120,39 \pm 1,56 \mathrm{bB}$ & $125,83 \pm 2,02 \mathrm{bA}$ \\
\hline Óleo de peixe & $112,39 \pm 1,71 \mathrm{aD}$ & $120,39 \pm 1,56 \mathrm{aC}$ & $130,82 \pm 2,20 \mathrm{aB}$ & $137,01 \pm 1,16 \mathrm{aA}$ \\
\hline \multirow{2}{*}{ Óleo de milho (50\%) mais óleo de peixe $(50 \%)$} & $112,84 \pm 1,56 \mathrm{aB}$ & $115,41 \pm 2,14 \mathrm{abB}$ & $123,56 \pm 1,79 \mathrm{bA}$ & $127,04 \pm 2,28 \mathrm{bA}$ \\
\hline & \multicolumn{4}{|c|}{$\mathrm{HDL}$} \\
\hline Óleo de oliva & $73,64 \pm 4,75 \mathrm{dA}$ & $74,38 \pm 1,66 \mathrm{dA}$ & $75,11 \pm 0,73 \mathrm{dA}$ & $74,83 \pm 0,54 \mathrm{dA}$ \\
\hline Óleo de milho & $78,92 \pm 0,54 \mathrm{cAB}$ & $78,69 \pm 0,76 \mathrm{cB}$ & $79,94 \pm 0,76 \mathrm{cAB}$ & $82,10 \pm 1,32 \mathrm{cA}$ \\
\hline Óleo de peixe & $94,49 \pm 0,52 \mathrm{aD}$ & $99,03 \pm 1,01 \mathrm{aC}$ & $105,80 \pm 1,42 \mathrm{aB}$ & $111,02 \pm 0,61 \mathrm{aA}$ \\
\hline \multirow[t]{2}{*}{ Óleo de milho $(50 \%)$ mais óleo de peixe $(50 \%)$} & $90,85 \pm 0,49 \mathrm{bB}$ & $91,99 \pm 1,26 \mathrm{bB}$ & $96,88 \pm 0,74 \mathrm{bA}$ & $97,39 \pm 0,67 \mathrm{bA}$ \\
\hline & \multicolumn{4}{|c|}{ LDL } \\
\hline Óleo de oliva & $10,41 \pm 1,45$ & $8,20 \pm 1,94$ & $9,78 \pm 1,45$ & $11,83 \pm 1,21$ \\
\hline Óleo de milho & $13,41 \pm 2,11$ & $16,72 \pm 3,17$ & $19,09 \pm 1,81$ & $20,66 \pm 1,63$ \\
\hline Óleo de peixe & $10,25 \pm 1,69$ & $10,74 \pm 0,98$ & $12,62 \pm 161$ & $12,78 \pm 1,50$ \\
\hline \multirow[t]{2}{*}{ Óleo de milho (50\%) mais óleo de peixe $(50 \%)$} & $9,78 \pm 1,45$ & $12,22 \pm 1,60$ & $14,20 \pm 1,30$ & $16,40 \pm 2,00$ \\
\hline & \multicolumn{4}{|c|}{ VLDL } \\
\hline Óleo de oliva & $6,74 \pm 0,88 \mathrm{cB}$ & $8,96 \pm 0,46 \mathrm{cB}$ & $12,24 \pm 0,61 \mathrm{bA}$ & $13,95 \pm 2,35 \mathrm{bA}$ \\
\hline Óleo de milho & $9,18 \pm 0,67 \mathrm{bC}$ & $15,61 \pm 0,77 \mathrm{aB}$ & $21,36 \pm 1,81 \mathrm{aA}$ & $23,07 \pm 1,32 \mathrm{aA}$ \\
\hline Óleo de peixe & $7,65 \pm 1,00 \mathrm{bcC}$ & $10,62 \pm 0,56 \mathrm{bcB}$ & $12,40 \pm 0,45 \mathrm{Bab}$ & $13,21 \pm 0,31 \mathrm{bA}$ \\
\hline Óleo de milho (50\%) mais óleo de peixe $(50 \%)$ & $12,21 \pm 0,54 \mathrm{aA}$ & $11,20 \pm 0,85 \mathrm{bA}$ & $12,49 \pm 1,00 \mathrm{bA}$ & $13,25 \pm 0,52 \mathrm{bA}$ \\
\hline
\end{tabular}

${ }^{(1)}$ Médias seguidas de letras iguais, maiúsculas nas linhas e minúsculas nas colunas, não diferem pelo teste de Tukey, a $5 \%$ de probabilidade.

Tabela 5. Atividade das enzimas málica e glicose-6-P desidrogenase ( $\mathrm{U} \mathrm{mg}^{-1}$ de proteína) no tecido hepático de pacu, de acordo com a dieta fornecida e o tempo de coleta $^{(1)}$.

\begin{tabular}{|c|c|c|c|c|c|}
\hline \multirow[t]{2}{*}{ Dieta } & \multicolumn{4}{|c|}{ Tempo de coleta (dias) } & \multirow[t]{2}{*}{ Médias } \\
\hline & 7 & 14 & 21 & 28 & \\
\hline Óleo de oliva & $0,064 \pm 0,004$ & $0,060 \pm 0,002$ & $0,047 \pm 0,002$ & $0,049 \pm 0,001$ & $0,055 \mathrm{~b}$ \\
\hline Óleo de milho & $0,088 \pm 0,005$ & $0,080 \pm 0,004$ & $0,042 \pm 0,005$ & $0,033 \pm 0,002$ & $0,061 \mathrm{a}$ \\
\hline Óleo de peixe & $0,026 \pm 0,001$ & $0,030 \pm 0,002$ & $0,016 \pm 0,001$ & $0,014 \pm 0,001$ & $0,022 \mathrm{c}$ \\
\hline Óleo de milho (50\%) mais óleo de peixe $(50 \%)$ & $0,026 \pm 0,003$ & $0,023 \pm 0,001$ & $0,022 \pm 0,002$ & $0,018 \pm 0,003$ & $0,022 \mathrm{c}$ \\
\hline \multirow[t]{2}{*}{ Médias $^{(2)}$} & 0,051 & 0,048 & 0,032 & 0,029 & \\
\hline & \multicolumn{5}{|c|}{ Glicose 6 P desidrogenase } \\
\hline Óleo de oliva & $0,356 \pm 0,020$ & $0,302 \pm 0,027$ & $0,285 \pm 0,002$ & $0,294 \pm 0,004$ & $0,309 \mathrm{a}$ \\
\hline Óleo de milho & $0,205 \pm 0,005$ & $0,187 \pm 0,009$ & $0,254 \pm 0,018$ & $0,218 \pm 0,018$ & $0,216 b$ \\
\hline Óleo de peixe & $0,098 \pm 0,006$ & $0,111 \pm 0,006$ & $0,105 \pm 0,005$ & $0,097 \pm 0,004$ & $0,103 \mathrm{c}$ \\
\hline Óleo de milho (50\%) mais óleo de peixe $(50 \%)$ & $0,130 \pm 0,005$ & $0,111 \pm 0,012$ & $0,141 \pm 0,005$ & $0,117 \pm 0,003$ & $0,125 \mathrm{c}$ \\
\hline Médias & 0,197 & 0,178 & 0,196 & 0,182 & \\
\hline
\end{tabular}


As enzimas lipogênicas avaliadas mostraram atividade hepática mais elevada nos animais que receberam dietas formuladas com óleo de oliva e óleo de milho, o que está relacionado à proporção diferenciada de ácidos graxos insaturados das fontes de óleo empregadas. As dietas formuladas com óleo de oliva e óleo de milho, isolados, apresentam altas proporções de ácidos graxos monoinsaturados e poli-insaturados ômega-6, com predisposição a uma maior atuação das enzimas que participam dos processos lipogênicos e do armazenamento lipídico. Pesquisas realizadas com ratos mostram que dietas com ácidos graxos poli-insaturados ômega-3 reduzem significativamente a lipogênese hepática (Zampelas et al., 1995). Isso explica, em parte, a menor atuação das enzimas lipogênicas nos peixes alimentados com dietas com óleo de peixe e com a mistura de óleos de peixe e de milho, ricas em ácidos graxos poli-insaturados ômega-3.

A atividade destas enzimas pode ser utilizada como indicador do status nutricional de algumas espécies (Méton et al., 2003; Sanden et al., 2003). Normalmente, é afetada pela temperatura da água e por fatores hormonais, mas, principalmente, pela composição da dieta e pela frequência de alimentação. No presente trabalho, observou-se efeito atribuído à composição da dieta, uma vez que os demais parâmetros foram controlados.

Em peixes, assim como em mamíferos, a participação da G6PD no fornecimento de energia para os processos lipogênicos é geralmente maior quando comparada à EM (Murray et al., 2008). No entanto, a contribuição desta última é essencial e pode variar de

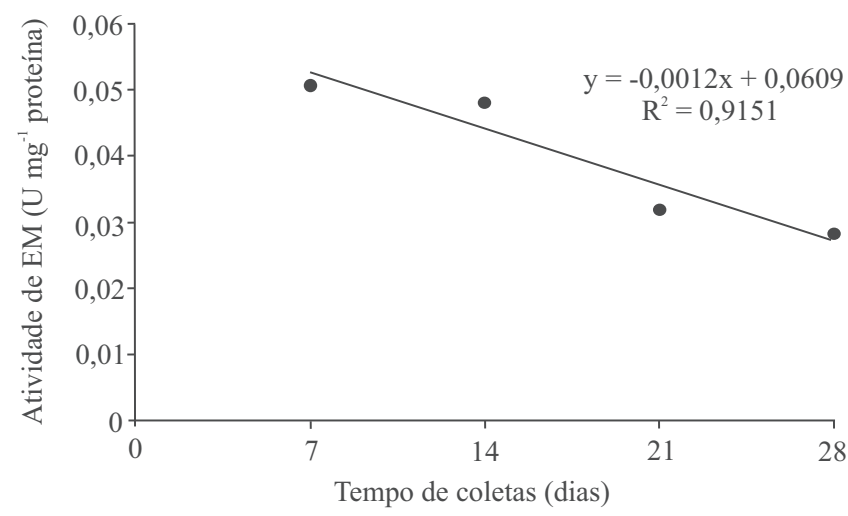

Figura 1. Atividade da enzima málica (EM) no tecido hepático de pacu, de acordo com o tempo de coleta. acordo com espécie, idade e estado fisiológico. Estudos com piracanjuba [Brycon orbignyanus (Vallenciennes, 1849)] apontam que a atividade da EM representa cerca de $50 \%$ da atividade da G6PD (Borba et al., 2003). Entretanto, Figueiredo-Silva et al. (2005) reportaram valores muito próximos de atividade de G6PD e de EM para trutas, com médias de 0,110 e $0,100 \mathrm{U} \mathrm{mg}^{-1}$ de proteína, respectivamente. Dados da literatura mostram que a atividade destas enzimas, para peixes, encontrase numa faixa de 0,109 a $0,920 \mathrm{U} \mathrm{mg}^{-1}$ de proteína, para G6PD, e de 0,013 a $0,082 \mathrm{U} \mathrm{mg}^{-1}$ de proteína para EM (Dias et al., 1998, 2004; Regost et al., 2001; Borba et al., 2003; Metón et al., 2003). Esta ampla variação ocorre em razão da diversidade das espécies estudadas e das condições experimentais em que os ensaios foram realizados. Regost et al. (2001), por exemplo, encontraram atividades médias de G6PD e de EM de 0,220 e $0,050 \mathrm{U} \mathrm{mg}^{-1}$ de proteína, respectivamente, em "turbot" (Psetta maxima) alimentados com óleo de peixe na dieta. Estes dados são os que mais se aproximam dos obtidos no presente trabalho, com animais alimentados com dieta formulada com óleo de peixe, de 0,125 e $0,022 \mathrm{U} \mathrm{mg}^{-1}$ de proteína para G6PD e EM, respectivamente.

\section{Conclusões}

1. O metabolismo lipídico do pacu é influenciado pela composição do lipídio da dieta, sobretudo as atividades de glicose-6-P desidrogenase e enzima málica.

2. A composição muscular dos pacus é reflexo da composição do lipídio da dieta.

3. Há evidências de maior deposição lipídica nos peixes alimentados com dietas ricas em ácidos graxos monoinsaturados e poli-insaturados ômega-6.

\section{Agradecimentos}

Ao Conselho Nacional de Desenvolvimento Científico e Tecnológico (CNPq), pelo apoio financeiro.

\section{Referências}

AIURA, F.S.; CARVALHO, M.R.B. de. Body lipid deposition in Nile tilapia fed on rations containing tannin. Pesquisa Agropecuária Brasileira, v.42, p.51-56, 2007. DOI: 10.1590/ S0100-204X2007000100007. 
BORBA, M.R. de; FRACALOSSI, D.M.; PEZZATO, L.E.; MENOYO, D.; BAUTISTA, J.M. Growth, lipogenesis and body composition of piracanjuba (Brycon orbignyanus) fingerlings fed different dietary protein and lipid concentrations. Aquatic Living Resources, v.16, p.362-369, 2003. DOI: 10.1016/ S0990-7440(03)00061-5.

BRADFORD, M.M. A rapid and sensitive method for the quantitation of microgram quantities of protein utilizing the principle of protein-dye binding. Analytical Biochemistry, v.72, p.248-254, 1976. DOI: 10.1016/0003-2697(76)90527-3.

DIAS, J.; ALVAREZ, M.J.; DIEZ, A.; ARZEL, J.; CORRAZE, G.; BAUTISTA, J.M.; KAUSHIK, S.J. Regulation of hepatic lipogenesis by dietary protein/energy in juvenile European seabass (Dicentrarchus labrax). Aquaculture, v.161, p.169-186, 1998. DOI: 10.1016/S0044-8486(97)00268-8.

DIAS, J.; RUEDA-JASSO, R.; PANSERAT, S.; CONCEIÇÃO, L.E.C.; GOMES, E.F.; DINIS, M.T. Effect of dietary carbohydrate-to-lipid ratios on growth, lipid deposition and metabolic hepatic enzymes in juvenile Senegalese sole (Solea senegalensis, Kaup). Aquaculture Research, v.35, p.1122-1130, 2004. DOI: $10.1111 /$ j.1365-2109.2004.01135.x.

FERREIRA, M.W.; ARAUJO, F.G. de; COSTA, D.V.; VIEIRA E ROSA, P.; FIGUEIREDO, H.C.P.; MURGAS, L.D.S. Influence of dietary oil sources on muscle composition and plasma lipoprotein concentrations in Nile Tilapia, Oreochromis niloticus. Journal of the World Aquaculture Society, v.42, p.24-33, 2011. DOI: 10.1111/j.1749-7345.2010.00440.x.

FIGUEIREDO-SILVA, A.C.; REMA, P.; BANDARRA, M.N.; NUNES, M.L.; VALENTE, L.M.P. Effects of dietary conjugated linoleic acid $\mathrm{n}$ growth, nutrient utilization, body composition, and hepatic lipogenesis in rainbow trout juveniles (Oncorhynchus mykiss). Aquaculture, v.248, p.163-172, 2005. DOI: 10.1016/j. aquaculture.2005.04.022.

FURUYA, W.M.; HAYASHI, C.; FURUYA, V.R.B. Exigência de proteína para alevino revertido de tilápia do Nilo (Oreochromis niloticus). Revista Brasileira de Zootecnia, v.29, p.1912-1917, 2000.

GILMAN, C.I.; LEUSCH, F.D.L.; BRECKENRIDGE, W.C.; MACLATCHY, D.I. Effects of a phytosterol mixture on male fish plasma lipoprotein fractions and testis P450scc activity. General and Comparative Endocrinology, v.130, p.172-184, 2003. DOI: 10.1016/S0016-6480(02)00590-7.

GRAEVE, K. Purification, characterization and cDNA sequence of glucose-6-phosphate dehydrogenase from potato (Solanum tuberosum L.). Plant Journal, v.5, p.353-361, 1994. DOI: 10.1111/j.1365-313X.1994.00353.x.

HORWITZ, W. (Ed.). Official methods of analysis of the AOAC International. $18^{\text {th }}$ ed. Washington: AOAC International, 2005. 1102 p.

JORDAL, A.E.O.; LIE, O.; TORSTENSEN, B.E. Complete replacement of dietary fish oil with a vegetable oil blend affect liver lipid and plasma lipoprotein levels in Atlantic salmon (Salmo salar L.). Aquaculture Nutrition, v.13, p.114-130, 2007. DOI: 10.1111/j.1365-2095.2007.00455.x.
LUZIA, L.A.; SAMPAIO, G.R.; CASTELLUCCI, C.M.N.; TORRES, E.A.F.S. The influence of season on the lipid profiles of five commercially important species of Brazilian fish. Food Chemistry, v.83, p.93-97, 2003. DOI: 10.1016/ S0308-8146(03)00054-2.

MENOYO, D.; LOPEZ-BOTE, C.J.; BAUTISTA, J.M.; OBACH, A. Growth, digestibility and fatty acid utilization in large Atlantic salmon (Salmo salar) fed varying levels of n-3 and saturated fatty acids. Aquaculture, v.225, p.295-307, 2003. DOI: 10.1016/ S0044-8486(03)00297-7.

MÉTON, I.; FERNÁDEZ, F.; BAANANTE, I.V. Shot- and long-term effects of refeeding on key enzyme activities in glycolysis-gluconeogenesis in the liver of gilthead seabream (Sparus auratus). Aquaculture, v.225, p.99-107, 2003. DOI: 10.1016/S0044-8486(03)00281-3.

MURRAY, R.K.; GRANNER, D.K.; RODWELL, V.W. Harper: bioquímica ilustrada. McGraw-Hill: Brasil, 2008. 632p.

PEREIRA, S.L.; LEONARD, A.E.; MUKERJI, P. Recent advances in the study of fatty acids desaturases from animals and lower eukaryotes. Prostaglandins, Leukotrienes and Essential Fatty Acids, v.68, p.97-106, 2003. DOI: 10.1016/ S0952-3278(02)00259-4.

REGOST, C.;ARZEL, J.; CARDINAL, M.; ROBIN, J.; LAROCHE, M.; KAUSHIK, S.J. Dietary lipid level, hepatic lipogenesis and flesh quality in turbot (Psetta maxima). Aquaculture, v.193, p.291-309, 2001. DOI: 10.1016/S0044-8486(00)00493-2.

RIBEIRO, P.A.P.; LOGATO, P.V.R.; PAULA, D.A. de J.; COSTA, A.C.; MURGAS, L.D.S.; FREITAS, R.T.F. de. Efeito do uso de óleo na dieta sobre a lipogênese e o perfil lipídico de tilápias-do-nilo. Revista Brasileira de Zootecnia, v.37, p.1331-1337, 2008. DOI: 10.1590/S1516-35982008000800001.

RICHARD, N.; KAUSHIK, S.; LARROQUET, L.; PANSERAT, S.; CORRAGE, C. Replacing dietary fish oil by vegetable oil has little effect on lipogenesis, lipid transport and tissue lipid uptake in rainbow trout (Oncorhynchus mykiss). British Journal of Nutrition, v.96, p.299-309, 2006a. DOI: 10.1079/BJN20061821.

RICHARD, N.; MOURENTE, G.; KAUSHIK, S.; CORRAZE, G. Replacement of a large portion of fish oil by vegetable oils does not affect lipogenesis, lipid transport and tissue lipid uptake in European seabass (Dicentrarchus labrax L.). Aquaculture, v.261, p.1077-1087, 2006b. DOI: 10.1016/j.aquaculture.2006.07.021.

SAEG: sistema para análises estatísticas e genéticas. Versão 9.1. Viçosa: UFV, 2007.

SÁNCHEZ-MUROS, M.J.; GARCÍA-REJÓN, L.; LUPIÀÑEZ, J.A.; LA HIGUEIRA, M. de. Long-term nutritional effects on the primary liver and kidney metabolism in rainbow trout (Oncorhynchus mykiss). II. Adaptive response of glucose 6-phosphate dehydrogenase activity to high-carbohydrate/ low-protein and high-fat/non-carbohydrate diets. Aquaculture Nutrition, v.2, p.193-200, 1996. DOI: 10.1111/j.1365-2095.1996. tb00059.x.

SANDEN, M.; FRØYLAND, L.; HEMRE, G.I. Modulation of glucose-6-phosphate dehydrogenase, 6-phosphogluconate dehydrogenase and malic enzyme activity by glucose and alanine 
in Atlantic salmon, Salmo salar L. hepatocytes. Aquaculture, v.221, p.469-480, 2003. DOI: 10.1016/S0044-8486(03)00077-2.

SPINA JUNIOR, J.; BRIGHT, H.J.; ROSENBLOOM, J. Purification and properties of L-malic enzyme from Escherichia coli. Biochemistry, v.9, p.3794-3801, 1970. DOI: 10.1021/ bi00821a019.

TOCHER, D.R. Metabolism and functions of lipids and fatty acids in teleost fish. Fisheries Science, v.11, p.107-184, 2003. DOI: 10.1080/713610925.

TORSTENSEN, B.E.; FRØYLAND, L.; LI, Ø. Replacing dietary fish oil with increasing levels of rapeseed oil and olive oil effects on Atlantic salmon (Salmo salar L.) tissue and lipoprotein lipid composition and lipogenic enzyme activities. Aquaculture
Nutrition, v.10, p.175-192, 2004. DOI: 10.1111/j.1365-2095.200 4.00289.x.

TORSTENSEN, B.E.; LIE, O.; HAMRE, K. A factorial experimental design for investigation of effects of dietary lipid content and pro- and antioxidants on lipid composition in Atlantic salmon (Salmo salar) tissues and lipoproteins. Aquaculture Nutrition, v.7, p.265-276, 2001. DOI: 10.1046/j.1365-2095.2001 .00184.x.

ZAMPELAS, A.; MORGAN, L.M.; FURLONGER, N.; WILLIAMS, C.M. Effects of dietary fatty acid composition on basal and hormone-stimulated hepatic lipogenesis and on circulating lipids in the rat. British Journal of Nutrition, v.74, p.381-392, 1995. DOI: 10.1079/BJN19950142.

$\overline{\text { Recebido em } 9 \text { de maio de } 2011 \text { e aprovado em } 27 \text { de setembro de } 2012}$ 